\title{
A Clinical Study of Chronic Headaches: Clinical Characteristics and Depressive Trends in Migraine \& Tension-Type Headaches
}

\author{
Young Chul Choi, Won Joo Kim, Chan Hyung Kim*, and Myung Sik Lee
}

\begin{abstract}
Background \& Objectives: Chronic headache is commonly encountered in the neurology outpatient clinic and it is often associated with depression. In Korea, however, chronic headache has not yet been systematically investigated. We conducted this study to investigate this clinical characteristics and level of depression in patients who presented migraine, tension-type headache, or transformed migraine.

Method: Among those with chronic headache during the period from January 11994 through December 31 1994, 131 patients were diagnosed to have either migraine, tension-type headache (by IHS classification), or transformed migraine: migraine in 60 patients, tension-type headache in 49 patients, and transformed migraine in 22 patients. Beck Depression Inventory (BDI) was performed in 116 of the 131 patients.

Results \& Conclusion: There was no significant difference in the age of onset, duration of headache, and family history among the three groups. However, patients with migraine had a more severe, unilateral, and throbbing characteristic pain than those with a tension-type headache. The mean BDI scores in the transformed migraine and the tension-type headache patients were significantly higher than those of migraine, but the level of depression did not correlate with the patient's age, duration, character, severity, and frequency of headache. These findings suggest that migraine, tension-type headache and transformed migraine may be considered clinically distinct entities in viewing their different clinical characteristics and level of depression.
\end{abstract}

Key Words: Migraine, tension-type headache, depression

The chronic primary headache disorders are by far the most common chronic pain syndrome which are encountered in the neurology outpatient clinic. Migraine and tension-type headaches are the most common and impor-

\section{Received October 24, 1995}

Accepted December 8, 1995

Department of Neurology and Psychiatry*, Yongdong Severance Hospital, Yonsei University College of Medicine

This study was supported by a funds of Yonsei University College of Medicine

Addrees reprint requests to Dr. Y.C. Choi ${ }_{1 \mathrm{i}}$ Department of Neurology, Yongdong Severance Hospital, Y̌onsei University College of Medicine, Yongdong C.P.O. Box 1217, Seoul 135-270, Korea tant headache syndromes, which sometimes interfere with daily activities. However, their clinical characteristics and prevalence have rarely been documented, especially in Korea.

The co-occurrence of migraine and tensiontype headache symptoms are commonly reported by patients. However, physicians usually record a single diagnosis of either migraine or tension-type headache. Depression and headache are also strongly associate (Diamond, 1983; Breslau, 1994). Not only are chronic headache sufferers frequently depressed but headache is the most common somatic symptom of depressed patients (Diamond, 1983). Clinical diagnosis of headache syndrome can be difficult. Therefore accurate headache di- 
agnosis is important to the physician in clinical practice and is essential to ensure proper treatment. Until 1988, the diagnosis of the Ad Hoc committee (1962) had been used, but it was found to be vague and too general. The operational criteria proposed by the Classification Committee of the International Headache Society (Headache classification committee of IHS, 1988) are more specific and clear. However, it has many practical problems in clinical application (Silberstein et al. 1994) for there are a large subset of patients with transformed migraine and chronic daily headache who do not meet the classification criteria (Silberstein et al. 1994).

The pathogenic mechanisms of migraine and tension-type headache are still controversial. Migraine and tension-type headache have long been considered distinct entities (Headache classification committee of IHS, 1988; Rasmussen et al. 1992). However, it is still unknown whether tension-type headache is a milder form of migraine or if it is a distinct entity. Some clinicians and epidemiologists believe that migraine and tension-type headaches represent ends of a nosologic spectrum and are not distinct entities (Featherstone, 1985). As headache frequency increases, the clinical distinction between migraine and tension-type headache becomes blurred. Some headaches occur daily or almost every day with occasional full-blown migraine attacks (Sheftell, 1992). The clinical syndrome of a headache with characteristic natural history and association with depression is called "transformed migraine", originally described by Mathew et al. (1982). We tried to compare the clinical characteristics and level of depression between chronic headache patients with migraine, tension-type headache, and transformed migraine to see whether they should be regarded as distinct entities or as part of a continuum.

\section{METHODS}

This study was done prospectively to evaluate chronic headache patients seen at the
Table 1. International headache society diagnostic criteria (Headache classification committee of IHS, 1988)

1. Migraine
A. At least 5 attacks fulfilling criteria below
B. Duration 4 72 hours
C. At least 2 of the following:
1. Unilateral location
2. Pulsating quality

3. Moderate to severe intensity(inhibits or prohibits daily activities

4. Aggravation by routine physical activity, such as walking stairs

D. At least 1 of the following:

1. Nausea and/or vomiting

2. The combination of photophobia and phonophobia

2. Tension-type
A. At least 10 attacks fulfilling criteria below
B. Duration 30 minutes to 7 days
C. At least 2 of the following:

1. Bilateral location

2. Nonpulsating pain

3. Mild to moderate intensity(may inhibit but not prohibit activities)

4. No aggravation by continuing routine activities

D. Both of the following:

1. No nausea or vomiting(anorexia may occur)

2. Either photophobia or phonophobia alone, but not the combination; or absence of both photophobia and phonophobia.

Yongdong Severence Hospital during the period from January 1, 1994 through December 31, 1994. The presence of symptomatic headaches was ruled out by means of history, physical and neurological examination, and radiological studies. 211 patients with chronic headaches had visited the clinic during the period above. These subjects were classified into headache subgroups according to a structured diagnostic headache interview which included: (a) migraine, (b) tension-type headache and (c) transformed migraine. For the diagnosis of headache, 'migraine' and 'tension-type headache' were defined by the optional diagnostic 
criteria of the International Headache Society (1988)(Table 1). 'Transformed migraine' was defined by patients who clearly identified having two distinct types of headache. The following categories of patients were excluded: (a) patients with headache chronicity of less than 6 months and (b) patients with primary headache disorders which could not be classified into the above subgroups. The interview of 131 patients who satisfied the above criteria focused primarily on frequency, intensity, duration, laterality, character of pain, aggravation, other ameliorating factors, and family history. The intensity of the headache was described in three groups: "mild pain" (daily activities not inhibited), "moderate pain" (inhibiting, but not preventing daily activities, and "severe pain" (daily activities suspended). Depression was measured by the Beck Depression Inventory (BDI) (Beck et al. 1961; Hahn et al. 1986) upon their first visit to our clinic. The BDI is a 21-item self reported system providing a quantitative assessment of the intensity of depression. The items of the BDI were chosen on the basis of their relationship to overt behavioral manifestations of depression and do not reflect any theory regarding the etiology or the underlying psychological processes in depression (Beck et al. 1961). Evidence suggests that the BDI may be the most accurate inventory in representing the breadth of depressive symptoms (Beck et al. 1961; Beck and Beck, 1972; Hahn et al. 1986).

The following statistical analysis of data was used: the chi-square test, regression and one-way anova. Five percent level of significance and $95 \%$ exact confidence interval using the binomial distribution were used.

\section{RESULTS}

The subjects were 131 patients who consisted of 33 men $(25.2 \%)$ and 98 women $(74.8 \%$ ). These patients were as follows: 60 patients with migraine $(45.8 \%), \cdot 49$ with tension-type headache $(37.4 \%)$, and 22 with transformed migraine $(16.8 \%)$. The mean age for patients with migraine, tension-type headache, and transformed migraine was $38.4 \pm 12.1,40.7 \pm 11.7$, and $41.1 \pm 12.0$ respectively. Their ages ranged from 12 to 68 and there was no significant difference between the groups $(p>0.05)$ (Table 2). There were also no significant difference in the mean age for onset and duration of the headache between the subgroups $(p>0.05)(\mathrm{Ta}$ ble 2).

\section{Characteristics of head pain}

Table 1 are the summarized numbers of patients who were diagnosed with migraine, tension-type headache, and transformed migraine according to the clinical features. The throbbing character of headache in migraine, tension-type headache, and transformed migraine was 52 patients in $60(86.7 \%), 14$ in $49(28.4 \%)$, and 20 in $22(90.9 \%)$. The intensity of pain in patients with migraine and transformed migraine was more severe than those with the tension-type headache $(p<0.05)($ Table 2$)$. The headache was unilateral in $70 \%$ of migraine and $72.7 \%$ in transformed migraine, whereas $63 \%$ were bilateral in the tension-type headache. Migraine and transformed migraine were apt to have a character of unilateral headache and tension-type headache were apt to have bilateral headache $(p<0.05)$ (Table 2). Twenty four $(25 \%)$ of 60 patients with migraine had a side shift of the headache (Table 2). The lasting time of the headache was almost within 3 days in migraine and variable in the tension-type headache and transformed migraine (Table 3). The attacks of headache were more frequent in patients with tensiontype headache and transformed migraine than those with migraine (Table 4). However, there was no significant relationship between headache and family history (Table 2). The aggravating factors for chronic headache were: emotional factors $(61.8 \%$ ), physical factors $(38.9$ $\%$ ), sleep factors $(29.8 \%)$, endocrine factors (28.6\%), food \& alcohol factors $(22.1 \%)$, weather $(21.3 \%)$, and seasonal factors $(11.4 \%)$. The ameliorating factors of headache were rest or sleep, only after taking a drug, and with the passage of time (Table 5).

\section{Depressive trends}

Depression in 116 patients of 131 patients, 
Clinical Characteristics and Depressive Trends in Chronic Headaches

Table 2. Characteristics of headache in patients with chronic headache

\begin{tabular}{|c|c|c|c|c|c|}
\hline Male: female & $\begin{array}{c}\text { Migraine } \\
(\mathrm{n}=60) \\
13: 47\end{array}$ & $\begin{array}{c}\text { Tension-type } \\
\text { headache } \\
(\mathrm{N}=49) \\
18: 31\end{array}$ & $\begin{array}{c}\text { Transformed } \\
\text { migraine } \\
(\mathrm{n}=22) \\
2: 20\end{array}$ & $\begin{array}{c}\text { Total } \\
(\mathrm{N}=131) \\
33: 98\end{array}$ & Probability** \\
\hline \multicolumn{6}{|l|}{ Age, y } \\
\hline Mean & 38.4 & 40.7 & 41.1 & 39.1 & $\mathrm{p}>0.05$ \\
\hline SD & 12.1 & 11.7 & 12.0 & 11.9 & \\
\hline Mean Age at onset, $y$ & 31.1 & 34.4 & 31.9 & 32.5 & $\mathrm{p}>0.05$ \\
\hline Headache mean duration, y & 7.3 & 6.3 & 9.3 & 7.3 & $\mathrm{p}>0.05$ \\
\hline Headache character & $60(100)$ & $49(100)$ & $22(100)$ & $131(100)$ & $\mathrm{p}<0.05$ \\
\hline Throbbing $(\%)$ & $52(86.7)$ & $14(28.4)$ & $20(90.9)$ & $86(65.7)$ & \\
\hline Non-throbbing $(\%)$ & $8(13.3)$ & $35(71.4)$ & $2(9.1)$ & $45(34.3)$ & \\
\hline Intensity & $60(100)$ & $49(100)$ & $22(100)$ & $131(100)$ & $\mathrm{p}<0.05$ \\
\hline Mild(\%) & $8(13.3)$ & $16(32.7)$ & $5(22.7)$ & $29(22.1)$ & \\
\hline Moderate $(\%)$ & $5(8.3)$ & $12(24.5)$ & $3(13.6)$ & $20(15.2)$ & \\
\hline Severe $(\%)$ & $47(78.3)$ & $21(42.8)$ & $14(63.6)$ & $82(62.7)$ & \\
\hline Unilaterality & $60(100)$ & $49(100)$ & $22(100)$ & $131(100)$ & $\mathrm{p}<0.05$ \\
\hline Unilateral $(\%)$ & $42(70)$ & $18(36.7)$ & $16(72.7)$ & $76(58.1)$ & \\
\hline Bilateral $(\%)$ & $18(30)$ & $31(63.3)$ & $6(27.3)$ & $55(41.9)$ & \\
\hline Side shift & $60(100)$ & $49(100)$ & $22(100)$ & $131(100)$ & $. p<0.05$ \\
\hline Shifting $(\%)$ & $27(45)$ & $4(8.2)$ & $6(27.3)$ & $37(28.2)$ & \\
\hline Non-shift $(\%)$ & $33(55)$ & $45(91.8)$ & $16(72.7)$ & $94(71.8)$ & \\
\hline Family history & $60(100)$ & $49(100)$ & $22(100)$ & $131(100)$ & $\mathrm{p}<0.05$ \\
\hline Present $(\%)$ & $25(41.5)$ & $20(40.8)$ & $10(45.5)$ & $55(42)$ & \\
\hline None $(\%)$ & $35(58.5)$ & $29(59.2)$ & $12(54.5)$ & $76(58)$ & \\
\hline
\end{tabular}

*: By chi-square tests

Table 3. Lasting time of headache

\begin{tabular}{lcccc}
\hline \hline & $\begin{array}{c}\text { Migraine } \\
(\mathrm{n}=60)\end{array}$ & $\begin{array}{c}\text { Tension-type } \\
\text { headache } \\
(\mathrm{N}=49)\end{array}$ & $\begin{array}{c}\text { Tránsformed } \\
\text { migraine } \\
(\mathrm{n}=22)\end{array}$ & $\begin{array}{c}\text { Total } \\
(\mathrm{N}=131)\end{array}$ \\
\hline Hours $(<6 \mathrm{hr})$ & 11 & 14 & 10 & 35 \\
1 day & 22 & 6 & 2 & 30 \\
1 3 days & 2 & 9 & 3 & 34 \\
4 6 days & 2 & 2 & 1 & 5 \\
1 week & 2 & 11 & 5 & 17 \\
Irregular & 1 & 7 & 1 & 10 \\
\hline
\end{tabular}


Young Chul Choi, et al.

Table 4. Frequency of headache

\begin{tabular}{lcccc}
\hline \hline & $\begin{array}{c}\text { Mension-type } \\
(\mathrm{n}=60)\end{array}$ & $\begin{array}{c}\text { Transformed } \\
\text { headache } \\
(\mathrm{n}=49)\end{array}$ & $\begin{array}{c}\text { migraine } \\
(\mathrm{n}=22)\end{array}$ & $\begin{array}{c}\text { Total } \\
(\mathrm{N}=131)\end{array}$ \\
\hline Daily & 7 & 31 & 12 & 50 \\
Weekly & 25 & 6 & 6 & 37 \\
Monthly & 25 & 8 & 2 & 35 \\
Less & 2 & 2 & 2 & 6 \\
Other & 1 & 2 & 0 & 3 \\
\hline
\end{tabular}

Table 5. Ameliorating factors of headache

\begin{tabular}{lcccc}
\hline \hline & $\begin{array}{c}\text { Migraine(\%) } \\
(\mathrm{n}=60)\end{array}$ & $\begin{array}{c}\text { Tension-type }(\%) \\
\text { headache } \\
(\mathrm{n}=49)\end{array}$ & $\begin{array}{c}\text { Transformed } \%) \\
\text { migraine } \\
(\mathrm{n}=22)\end{array}$ & $\begin{array}{c}\text { Total }(\%) \\
(\mathrm{N}=131)\end{array}$ \\
\hline 1) Rest/sleep & $10(16.7)$ & $6(12.2)$ & $5(22.7)$ & $21(16)$ \\
2) Quiet & $1(1.7)$ & $3(6.1)$ & $0(0)$ & $4(3.1)$ \\
3) Compression & $4(6.7)$ & $0(0)$ & $2(9.1)$ & $6(4.6)$ \\
4) Drug & $15(25)$ & $4(8.2)$ & $2(9.1)$ & $21(16)$ \\
5) None & $18(30)$ & $21(42.9)$ & $8(36.3)$ & $47(35.9)$ \\
6) Other & $12(20)$ & $15(30.6)$ & $5(22.7)$ & $32(24.4)$ \\
\hline
\end{tabular}

Table 6. Depressive trends in patients with chronic headache

\begin{tabular}{|c|c|c|c|c|}
\hline & & & BDI score & Probability* \\
\hline \multirow[t]{2}{*}{ Character } & Throbbing & $(\mathrm{N}=79)$ & $14.43 \pm 5.56$ & \\
\hline & Non-throbbing & $(\mathrm{N}=37)$ & $14.98 \pm 7.23$ & $\mathrm{p}>0.05$ \\
\hline \multirow[t]{3}{*}{ Intensity } & Mild & $\mathrm{N}(=25)$ & $14.68 \pm 6.46$ & \\
\hline & Moderate & $(\mathrm{N}=17)$ & $14.88 \pm 7.83$ & \\
\hline & Severe & $(\mathrm{N}=74)$ & $14.83 \pm 6.62$ & $\mathrm{p}>0.05$ \\
\hline \multirow[t]{4}{*}{ Frequency } & Daily & $(\mathrm{N}=42)$ & $15.35 \pm 6.48$ & \\
\hline & Weekly & $(\mathrm{N}=35)$ & $16.28 \pm 7.36$ & \\
\hline & Monthly & $(\mathrm{N}=31)$ & $12.29 \pm 5.44$ & \\
\hline & Other & $(\mathrm{N}=8)$ & $15.25 \pm 7.94$ & $\mathrm{p}>0.05$ \\
\hline \multirow[t]{2}{*}{ Family history } & Present & $(\mathrm{N}=47)$ & $14.42 \pm 6.45$ & \\
\hline & None & $(\mathrm{N}=69)$ & $15.07 \pm 6.91$ & $\mathrm{p}>0.05$ \\
\hline Total & & $(\mathrm{N}=116)$ & $14.81 \pm 6.71$ & \\
\hline
\end{tabular}

\footnotetext{
*: By chi-square tests
} 
Table 7. Beck depression inventory score in patients with migraine, tension-type headache and transformed migraine

\begin{tabular}{lllc}
\hline \multicolumn{2}{c}{ Type of headache } & BDI score* & Renges \\
\hline $\begin{array}{l}\text { Migraine } \\
\text { Tension-type } \\
\text { headache }\end{array}$ & $(\mathrm{N}=57)$ & $12.52 \pm 6.43$ & $2 \sim 28$ \\
$\begin{array}{l}\text { Transformed } \\
\text { migraine }\end{array}$ & $(\mathrm{N}=20)$ & $20.75 \pm 6.57$ & $10 \sim 36$ \\
\hline Total & $(\mathrm{N}=116)$ & $14.81 \pm 6.71$ & $2 \sim 36$ \\
\hline
\end{tabular}

*: $p<0.05$ by one-way anova

consisting of 57 patients with migraine, 39 patients with tension-type headache, and 20 patients with transformed migraine. In 116 patients, BDI scores did not correlate with the patient's age, duration, character, intensity and frequency of headache, and family history ( $p>$ 0.05)(Table 6). The mean BDI score of the migraine, tension-type headache, and transformed migraine were $12.52 \pm 6.43,15.10 \pm 5.22$, and $20.75 \pm 6.57$ respectively (Table 7). Patients with tension-type headache and transformed migraine had a significantly higher mean BDI score compared to those of migraine.

\section{DISCUSSION}

The correlation between headache and depression has been well recognized (Merikangas et al. 1988; Marchesi et al. 1989) but there has been controversy in whether this relationship reflects pathology which pre-existed the headache disorder, the consequences of livings with chronic pain, or the contribution to both pain and depression resulting from deficient levels of brain serotonin and/or other neurotramsitters Jahanshahi and Philips, 1985; Glover et al. 1993; Silberstein, 1993; Manna et al. 1994). In this study, no significant correlation was found between depressive trends with patient's ages, duration, character, severity, frequency of headache, and family history. This result suggests that the level of depres- sion does not simply correlate with the headache itself.

Previous studies have suggested that migraine and tension-type headache are not separate clinical entities but part of a continuum of headache disorders varying in severity (Philips, 1977). Mathew et al. (1982) introduced the concept of transformation headache, establishing that intermittent headache frequently was transformed over time to a daily headache. However, in the new headache classification (Headache classification committee of IHS, 1988), this term was abandoned because of the lack of evidence for a separate specific entity. Our study contradicts to the clinical continuum of migraine and tensiontype headache in several ways. Not only were the clinical characteristics different, but also the level of depression was different between migraine and tension-type headaches. There were also a different sex distribution of $\mathrm{mi}$ graine (male-female ratio, 2: 8), tension-type headache (male-female ratio, 4: 7), and transformed migraine (male-female ratio, 1: 10). Clinical characteristics of patients with migraine have more severe, throbbing, unilateral, side sifting headache than the others. Patients with tension-type headache have mild, nonthrobbing, bilateral and short lasting headaches. Patients with transformed migraine have more severe, throbbing, unilateral and frequent headaches. Patients with transformed migraine and tension-type headache are much more likely than those with migraine to have a high level of depression. It is, therefore, highly probable that migraine and tensiontype headache may be considered separate clinical entities. Although our study does not definitely support that the transformed migraine is either a specific entity or a coexisting migraine, tension-type headache and transformed migraine should be considered clinically as a distinct entity in view of having a characteristic clinical syndrome with high level of depression. Further studies are needed to verify the possible association of headache and depression and to find the patholophysiologic mechanisms underlying depression. 


\section{REFERENCES}

Ad Hoc Committee: Classification of headache. JAMA 179: 717-718, 1962

Beck AT, Beck RW: Screening depressed patients in family practice: a rapid technic. Postgrad Med 52: 81-85, 1972

Beck AT, Ward CH, Mendelson M, Mock J, Erbaugh J: An inventory for measuring depression. Arch Gen Psychiatry 4: 561-571, 1961

Breslau N, Davis GC, Schultz LR, Peterson EL: Migraine and major depression: A longitudinal study. Headache 34: 387-393, 1994

Diamond S: Depression and headache. Headache 23: 122-126, 1983

Featherstone HJ: Migraine and muscle contraction headache: a continuum. Headache 24: 194-198, 1985

Glover V, Jarman J, Sandler M: Migraine and depression: Biological aspects. $J$ Psychiatry Res 27 : 223-231, 1993

Hahn HM, Yum TH, Shin TW, Kim KH, Yoon DJ, Chung KJ: A standardization study of Beck depression inventory in Korea. Korean $J$ Neuropsychiatr 25: 487-502, 1986

Headache classification committee of the International Headache Society: Classification and diagnostic criteria for headache disorders, cranial neurologias and facial pain. Cephalalgia 8 Suppl
7): 29-34, 1988

Jahanshahi M, Philips HC: The effects of persistent pain: the chronic headache sufferer. Pain 21: 163-176, 1985

Manna V, Bolino F, Cicco LD: Chronic tension-type headache, mood depression and serotonin: Therapeutic effects of Fluvoxamine and Mianserine. Headache 34: 44-49, 1994

Marchesi C, De Ferri A, Oetrolini N, Govi A, Manzoni GC, Coiro V, De Risio C: Prevalence of migraine and muscle tension headache in depressive disorders. J Affect. Disord 16: 433-436, 1989

Mathew NT, Stubits E, Nigam MR: Transformation of episodic migraine into daily headache: analysis of factors. Headache 22: 66-68, 1982

Merikangas KR, Rish NJ, Merikangas JR: Migraine and depression: association and familial transmission. J Psychiatr Res 22: 119-129, 1988

Philips C: Headache in general practice. Headache 16: 322-329, 1977

Rasmussen BK, Jensen R, Schroll M, Olesen J: Interrelations between migraine and tension-type headache in the general population. Arch Neurol 49: 914-918, 1992

Sheftell F: Chronic daily headache. Neurology 42 (Suppl 2): 32-36, 1992

Silberstein SD: Tension-type and chronic daily headache. Neurology 43: 1644-1649, 1993

Silberstein SD, Lipton RB, Solomon S, Mathew NT: Classification of daily and near-daily headache: Proposed revisions to the IHS criteria. Headache 34: 1-7, 1994 